\title{
C677T mutation in the 5,10-MTHFR gene and risk of Down syndrome in Italy
}

\author{
Liborio Stuppia ${ }^{1,2}$, Valentina Gatta ${ }^{1}$, Anna Rita Gaspari ${ }^{1}$, Ivana Antonucci ${ }^{1}$, \\ Elisena Morizio ${ }^{1,3}$, Giuseppe Calabrese ${ }^{1,3}$ and Giandomenico Palka ${ }^{\star 1,3}$
}

${ }^{1}$ Dipartimento di Scienze Biomediche, Sezione di Genetica Medica, Università 'G. D'Annunzio', Chieti, Italy; ${ }^{2}$ Istituto di Citomorfologia Normale e Patologica C.N.R., Chieti, Italy; ${ }^{3}$ Servizio di Genetica Umana, Ospedale Civile, Pescara, Italy

The C677T polymorphism of the MTHFR gene has been associated to maternal risk of Down syndrome, due to the detection of an higher prevalence of the $T$ allele among mothers of children with trisomy 21, compared to control mothers. In order to confirm this association, we studied the presence of the C677T in 64 mothers of Down syndrome children and 112 controls from central Italy. An higher incidence of the mutant T allele in controls (48.2\%) than in Down syndrome children mothers (44\%) was detected. These results do not support the presence of an increased risk of Down syndrome in mothers carriers of the $T$ allele in the Italian population.

European Journal of Human Genetics (2002) 10, 388 - 390. doi:10.1038/sj.ejhg.5200819

Keywords: Down syndrome; MTHFR gene; C677T mutation

\section{Introduction}

Methylenetetrahydrofolate reductase (MTHFR) has a crucial role in regulating cellular methylation, through the conversion of 5,10 methyl-THF to 5-methyl-THF, the methyl donor in the transformation of homocysteine to methionine. ${ }^{1}$ The C-T common polymorphism at nucleotide 677 (C677T), which results into an alanine to valine substitution in the MTHFR protein, causes higher thermolability and reduced enzyme activity in lymphocyte extracts. ${ }^{2}$ Increased folic acid intake is required to maintain homocysteine remethylation to methionine at normal levels. Reduced MTHFR activity due to the C677T change has been associated with different disorders, including vascular diseases, ${ }^{2}$ neural tube defects, ${ }^{3-5}$ male infertility. ${ }^{6}$ However, studies performed in different populations have often shown

\footnotetext{
*Correspondence: Professor G Palka; Dipartimento di Scienze Biomediche, Sezione di Genetica Medica, Università 'G. D'Annunzio', Via dei Vestini 35, 66013, Chieti, Italy. Tel: (39) 0871 3554137; Fax: (39) 0871 3554135; E-mail: gdpalka@unich.it Received 20 November 2001; revised 12 February 2002; accepted 10 April 2002
}

inconsistent results, disputing these associations. ${ }^{7-10}$ Recently, the C677T polymorphism has been related also to maternal risk for Down syndrome (DS), because of an higher prevalence of the $\mathrm{T}$ allele among mothers of children with trisomy 21, compared to control mothers. ${ }^{11,12}$ The hypothetical effect of $677 \mathrm{~T}$ onto maternal non-disjunction was linked to an altered DNA methylation pattern on the oocyte, secondary to reduced MTHFR activity. Available results refer only to DS and control mothers from USA and Canada. Recently, Hassold et al ${ }^{13}$ analysed maternal polymorphism at MTHFR in cases of trisomies of other chromosomes, detecting significant association only with trisomy 18 . The identification of the C677T as a factor of maternal risk for DS would be of great importance in the genetic counselling of this disease, since in this case other female relatives of a carrier DS mother should be tested for the presence of this mutation. In order to support the association between the MTHFR genotype and the risk of DS, we investigated the prevalence of the C677T polymorphism in a sample of Italian mothers of DS children. 
Table 1 Prevalence of the MTHFR genotypes in DS mothers and controls

\begin{tabular}{|c|c|c|c|c|c|c|c|c|}
\hline \multirow[b]{2}{*}{ Genotype } & \multicolumn{4}{|c|}{ DS mothers $(\boldsymbol{n}=64)$} & \multicolumn{4}{|c|}{ Controls $(n=112)$} \\
\hline & C/C (\%) & $C / T(\%)$ & $T / T(\%)$ & $C / T+T / T(\%)$ & C/C (\%) & $\mathrm{C} / \mathrm{T}(\%)$ & $T / T(\%)$ & $C / T+T / T(\%)$ \\
\hline James et $a l^{11}$ & 26.3 & 59.6 & 14 & 73.6 & 48 & 44 & 8 & 52 \\
\hline Hobbs et $a l^{12}$ & 32 & 54 & 14 & 68 & 48 & 42 & 10 & 52 \\
\hline
\end{tabular}

\section{Materials and methods}

Sixty-four mothers of trisomy 21 children and 112 controls from the Abruzzo region in central Italy entered this study. Karyotypes of DS parents were normal. The mean age at conception of case mothers was 30.9 years (range 20-46) and 50 mothers were less than 35 years. Informed consent was obtained from all the participants. The 112 controls were mothers with the same mean age, who had unremarkable pregnancy.

MTHFR genotypes were analysed on DNA from peripheral blood cells of mothers by PCR amplification of a 198 bp fragment, followed by Hinfl restriction endonuclease digestion. ${ }^{2}$ After digestion, samples were run on a $4 \%$ agarose or $8 \%$ polyacrilamyde gels. Allele frequencies were calculated for each genotype, and the $\chi^{2}$ test was used for evaluating the differences in allele frequencies between case and control mothers.

\section{Results}

In the case mothers, the $\mathrm{C} / \mathrm{C}$ wild homozygous genotype was found in $31 \%$, the $\mathrm{C} / \mathrm{T}$ heterozygous genotype in $50.7 \%$ and the $\mathrm{T} / \mathrm{T}$ mutant homozygous genotype in $18.3 \%$. In the mothers of DS children aged less than 35 years at conception, the $\mathrm{C} / \mathrm{C}$ genotype frequency was $32.5 \%, \mathrm{C} / \mathrm{T} 46.1 \%$, and $\mathrm{T} / \mathrm{T} 21.4 \%$. In the control mothers, the $\mathrm{C} / \mathrm{C}$ genotype frequency was $24.1 \%, \mathrm{C} / \mathrm{T} 55.4 \%$ and $\mathrm{T} / \mathrm{T}$ $20.5 \%$ (Table 1). Genotypes of control mothers were in the Hardy Weinberg equilibrium $\left(\chi^{2}=1.16, P>0,2\right)$. Overall, the frequency of the $\mathrm{C}$ allele was $56 \%$ in DS mothers and $51.8 \%$ in control mothers, while the frequency of the $\mathrm{T}$ allele was $44 \%$ in DS mothers and $48.2 \%$ in the control mothers (Table 2).

\section{Discussion}

Data obtained in this study does not support an increase of DS in the children of mothers with the $\mathrm{T}$ allele in our sample, the $\mathrm{C} / \mathrm{T}$ or $\mathrm{T} / \mathrm{T}$ genotypes being more common in controls than in DS children mothers. Conversely, we have detected a quite high frequency of the $\mathrm{T}$ allele in controls and a lower frequency in mothers of DS patients. This is a point of interest since the genotypes in the mothers of DS children were comparable to those reported by James et $a l^{11}$ and Hobbs et $a l^{12}$ while controls disclosed an higher frequency of the $\mathrm{T}$ allele, the $\mathrm{C} / \mathrm{T}$ and $\mathrm{T} / \mathrm{T}$ genotypes accounting for $75.9 \%$ of the analysed controls. The difference between case and controls was not significant
Table 2 Allele frequency of MTHFR $677 \mathrm{C}->\mathrm{T}$ in DS mothers and controls

\begin{tabular}{lllll}
\hline Allele & DS mothers & Controls & $\chi^{2}$ & $\boldsymbol{P}$ \\
\hline $\mathrm{C}$ & 0.56 & 0.52 & & \\
$\mathrm{~T}$ & 0.44 & 0.48 & 0.6 & $>0.2$ \\
\hline
\end{tabular}

$\left(\chi^{2}=2.59, P>0,05\right)$, even considering only mothers aged less than 35 years $\left(\chi^{2}=3.11, P>0,05\right)$.

These data confirm previous studies by showing an high prevalence of the $\mathrm{T}$ allele in the Italian population. ${ }^{5,14-16}$ Present results do not rule out an effect of the $677 \mathrm{~T}$ allele on maternal non disjunction, but suggest that in populations with adequate folate dietary intake the reduced enzymatic activity of the MTHFR in the carriers of the T allele is balanced by folates, thus reducing the risk of cellular demethylation and non disjunction. This also agrees with the observation that, despite an higher prevalence of the $677 \mathrm{~T}$ in Italy, compared to other European countries, the prevalence of neural tube defects is not increased in the Italian population. ${ }^{5}$ Thus, genotyping of the MTHFR gene at present does not appear useful to identify women with increased risk of non disjunction in Italian subjects.

\section{References}

1 Finkelstein JD: Methionine metabolism in mammals. $J$ Nutr Biochem 1990; 1: $228-237$.

2 Frosst P. Blom HJ, Milos R et al: A candidate genetic risk for vascular disease: a common mutation in methylenetetrahydrofolate reductase. Nat Genet 1995; 10: 111-113.

3 Van der Put NM, Steegers-Theunissen RPM, Frosst P et al: Mutated methylenetetrahydrofolate reductase as a risk factor for spina bifida. Lancet 1995; 346: 1070-1071.

4 Kirke PN, Mills JL, Whitehead AS, Molloy A, Scott JM: Methylenetetrahydrofolate reductase mutation and neural tube defects. Lancet 1996; 348: $1037-1038$.

5 De Franchis R, Buoninconti A, Mandato C et al: The C677T mutation of the 5,10- methylenetetrahydrofolate reductase gene is a moderate risk factor for spina bifida in Italy. J Med Genet 1998; 35: $1009-1013$.

6 Bezold G, Lange M, Peter RU: Homozygous methylenetetrahydrofolate reductase C677T mutation and male infertility. N Engl JMed 2001; 344: $1172-1173$.

7 Mornet E, Muller F, Lenvoise-Furet A et al: Screening of the C677T mutation on the methylenetetrahydrofolate reductase gene in French patients with neural tube defects. Hum Genet 1997; 100: 512-514. 
8 Speer MC, Warley G, Mackey JF, Melvin E, Oakes JW, George TM the NTD Collaborative Group: The thermolabile variant of methylenetetrahydrofolate reductase (MTHFR) is not a major risk factor for neural tube defects in American Caucasians. Neuro-genetics 1997; 1: $149-150$.

9 Wetkamp LR, Tackels DC, Hunter AGW, Holmes LB, Schwartz CE: Heterozygote advantage of the MTHFR gene in patients with neural-tube defects and their relatives. Lancet 1998; 351: 1554-1555.

10 Papapetrou C, Lynch SA, Burn J, Edwards YM: Methylenetetrahydrofolate reductase and neural tube defects. Lancet 1996; 348:58.

11 James SJ, Pogribna M, Pogribny IP et al: Abnormal folate metabolism and mutation in the methylenetetrahydrofolate reductase (MTHFR) gene may be maternal risk factors for Down syndrome. Am J Clin Nutr 1999; 70: 495-501.

12 Hobbs CA, Sherman SL, Yi P et al: Polymorphisms in genes involved in folate metabolism as maternal risk factors for Down syndrome. Am J Hum Genet 2000; 67: 623-630.
13 Hassold TJ, Burrage LC, Chan ER et al: Maternal folate polymorphisms and the etiology of human nondisjunction. Am J Hum Genet 2001; 69: 434-439.

14 Sacchi E, Tagliabue L, Duca F, Mannucci PM: High frequency of the C677T mutation in the methylenetetrahydrofolate reductase (MTHFR) gene in Northern Italy. Thromb Haemost 1997; 78: 963 964.

15 Tosetto A, Missiaglia E, Frezzato M, Rodeghiero F: The VITA project: C677T mutation in the methylenetetrahydrofolate reductase gene and risk of venous thromboembolism. Br J Haematol 1997; 97: 804-806.

16 De Franchis R, Sebastio G, Mandato C, Andria G, Mastroaicovo P: Spina bifida, $677 \mathrm{C}->\mathrm{T}$ mutation, and the role of folate. Lancet 1995; 346: 1073. 